\title{
Avaliação de materiais genéticos visando à produção de frango caipira em diferentes sistemas de alimentação
}

\section{Vicente José Maria Savino", Antonio Augusto Domingos Coelho', Millor Fernandes do Rosário², Marco Aurélio Neves da Silva ${ }^{3}$}

\author{
${ }^{1}$ Docente - Escola Superior de Agricultura "Luiz de Queiroz" (ESALQ/USP) - Departamento de Genética. Av: Pádua Dias, 11, Vila \\ Independência, 13418-900, Piracicaba/SP. \\ 2 Doutorando (Bolsista FAPESP) - ESALQ/USP - Departamento de Zootecnia - Laboratório de Biotecnologia Animal. \\ ${ }^{3}$ Doutor em Agronomia - ESALQ/USP - Departamento de Genética.
}

\begin{abstract}
RESUMO - Avaliaram-se genótipos experimentais e comerciais recomendados para criação no sistema caipira submetidos a dois programas de alimentação (convencional e alternativo) para simular condições de criação praticadas comumente pelos produtores. Até os 28 dias de idade, o delineamento utilizado foi o inteiramente casualizado e, dos 29 aos 84 dias de idade, foi o inteiramente casualizado em esquema fatorial $8 \times 2$ (oito genótipos: Paraíso Pedrês, Caipirão da ESALQ, 7 P, Embrapa 041, Label Rouge, Paraíso Pelado, Caipirinha da ESALQ e Carijó Barbada e dois programas de alimentação), ambos com duas repetições, considerando o boxe com 30 aves a unidade experimental. O peso vivo médio e a conversão alimentar obtidos nos períodos de 0 a 28,0 a 56 e de 0 a 84 dias foram submetidos à análise de variância e à comparação de médias. Constatou-se efeito da alimentação nos períodos de 0 a 56 e de 0 a 84 dias para ambas as variáveis. O genótipo teve efeito para as duas variáveis no período de 0 a 28 dias e apenas para peso vivo médio nos períodos de 0 a 56 e de 0 a 84 dias de idade. Verificou-se efeito das interações genótipo $\times$ alimentação sobre a conversão alimentar no período de 0 a 56 dias e para ambas as variáveis no período de 0 a 84 dias de idade. No período de 0 a 28 dias, os genótipos Paraíso Pedrês e Caipirão da ESALQ apresentaram os maiores pesos médios. No período de 0 a 56 dias, o genótipo Paraíso Pedrês apresentou maior peso médio e todos os genótipos diferiram entre os programas de alimentação quanto à conversão alimentar. Os genótipos Caipirão da ESALQ, Paraíso Pedrês e $7 \mathrm{P}$ apresentaram maiores pesos médios aos 84 dias de idade; nessa idade, todos os genótipos diferiram entre os programas de alimentação quanto à conversão alimentar. A substituição total da ração por milho afetou negativamente o desempenho das aves, no entanto, esse efeito foi menor no genótipo Paraíso Pedrês. O desempenho dos oito genótipos avaliados foi condicionado pelos fatores genética e alimentação.
\end{abstract}

Palavras-chave: desempenho, melhoramento genético de aves, nutrição, sistema de produção

\section{Evaluation of genetic populations of chicken to different diets in free-range broiler production systems}

\footnotetext{
ABSTRACT - The aim of the current study was to evaluate the performance of experimental and commercial genotypes of chicken recommended for free-range rearing system submitted to two diet programs (conventional and alternative). The experimental design consisted of a randomized design applied until 28 days and a randomized factorial $8 \times 2$ design (eight genotypes: Paraíso Pedrês, Caipirão da ESALQ, 7 P, Embrapa 041, Label Rouge, Paraíso Pelado, Caipirinha da ESALQ and Carijó Barbada and two diet programs), using two replicates with 30 chickens/box as experimental unit, from 29 to 84 days of age. Average body weight and feed:gain ratio were recorded during three periods: 1) 0-28,2) 0-56 and 3) 0-84 days and submitted to the analysis of variance. The effect of diet was evidenced for all traits in periods 2 and 3 . The effect of genotype was verified for all variables in period 1, but only for average body weight in periods 2 and 3 . The interaction genotype and diet was observed for feed:gain ratio in period 2 and for all traits in period 3. Paraíso Pedrês and Caipirão from ESALQ presented higher average body weight than the other genotypes in period 1. In period 2, Paraíso Pedrês presented the highest average body weight and all genotypes differed for feed:gain ratio. Caipirão from ESALQ, Paraíso Pedrês and 7 P presented higher average body weight than the other genotypes and all strains differed for feed:gain ratio in period 3. The full substitution of conventional diet by corn led to a worse chicken performance. Overall performance of the evaluated genotypes was conditioned by genetic and nutrition factors, with the lowest negative effects of substitution of conventional diet by corn on all traits in the Paraíso Pedrês genotype.
}

Key Words: nutrition, performance, poultry breeding, production system 


\section{Introdução}

Atualmente, consumidores têm demandado por alimentos mais saudáveis, produzidos de acordo com regras mínimas de segurança alimentar, segundo normas de criação que garantam o bem-estar animal, o que resulta em um produto final com características diferenciadas (Alroe et al., 2001; Lund \& Röcklingsberg, 2001; Hermansen, 2003; Stringheta \& Muniz, 2004).

Assim, a criação alternativa de frangos de corte, também chamados no Brasil de "caipira" (Região Sudeste), “colonial” (Região Sul) e "capoeira” (Região Nordeste), tem evoluído nos últimos anos, tornando-se uma atividade economicamente viável para pequenas propriedades rurais que podem explorar este nicho de mercado com produtos diferenciados (Figueiredo et al., 2001; Takahashi, 2003). Para se obter lucratividade neste segmento da avicultura, pesquisas na área de genética têm sido realizadas com o objetivo de desenvolver aves mais adaptadas para melhoria dos índices produtivos da criação alternativa (Farmer et al., 1997; Lewis et al., 1997; Boelling et al., 2003).

Além da genética, outro aspecto a ser considerado é o tipo de alimentação ao longo do período de criação. Silva \& Nakano (1998) e Figueiredo \& Ávila (2001) relataram haver diferenças entre os sistemas intensivo e semi-intensivo de criação de frangos, pois, no sistema semi-intensivo, por terem acesso à pastagem, as aves acabam ingerindo outros alimentos, como verduras, insetos e minhocas. Além disso, os produtores desse sistema costumam substituir a ração por quirera ou milho em grão na tentativa de reduzir os custos de alimentação. Obviamente, com a adoção desta prática, o desempenho das aves fica condicionado à complementação alimentar advinda da pastagem, o que não evita perdas nos índices de desempenho.

A avaliação econômica do sistema semi-intensivo, apesar de sua reconhecida relevância (tem-se buscado a redução de custos, principalmente dos relacionados à alimentação), tem sido pouco divulgada, o que torna os resultados restritos regionalmente, dificultando qualquer tipo de comparação. Salienta-se que o frango caipira não compete com o frango industrial em escala de produção e custo, mas sim em qualidade da carne, principalmente sabor, atendendo a consumidores que podem pagar mais pelo produto com essas características (Gessulli, 1999).

Este trabalho foi realizado com o objetivo de avaliar o desempenho de genótipos experimentais e comerciais recomendados para criação no sistema caipira submetidos a dois programas de alimentação.

\section{Material e Métodos}

O experimento foi conduzido utilizando-se aves provenientes de ovos de oito genótipos de frangos caipiras. Os ovos foram incubados simultaneamente no Departamento de Genética da Escola Superior de Agricultura "Luiz de Queiroz"(ESALQ/USP), em Piracicaba/SP.

Foram utilizados 960 pintos não sexados (120 de cada genótipo) vacinados contra Marek, Bouba, Gumboro e Newcastle, alojados em 32 boxes ( 30 aves por boxe) com área interna de $3 \mathrm{~m}^{2}$, onde receberam alimento e água ad libitum ao longo de todo o período experimental. $\mathrm{O}$ acesso das aves aos piquetes $\left(30 \mathrm{~m}^{2}\right.$ de área externa por boxe) com cobertura vegetal (constituída predominantemente das gramas estrela e batatais) foi permitido no período dos 14 dias de idade até o final do período experimental.

O delineamento experimental empregado até os 28 dias de idade foi o inteiramente casualizado. Dos 29 aos 84 dias de idade, adotou-se o delineamento inteiramente casualizado em esquema fatorial $8 \times 2$ (oito genótipos e dois programas de alimentação). Ambos os delineamentos constaram de duas repetições por tratamento, considerando o boxe com 30 aves a unidade experimental.

A descrição de cada material genético utilizado neste trabalho é feita a seguir:

- Caipirão da ESALQ: população melhorada para corte, de crescimento rápido e de fenótipos variados para cor de plumagem;

- 7 P - Pinto Preto Pesado de Pasto de Pescoço Pelado de Piracicaba: população melhorada para corte, de crescimento rápido e de plumagem preta, apresentando o gene do pescoço pelado;

- Caipirinha da ESALQ: população melhorada para dupla aptidão (corte e postura), de crescimento lento e de fenótipos variados para cor de plumagem, apresentando o gene que confere topete e o gene do pescoço pelado;

- Carijó Barbada: população melhorada para dupla aptidão (corte e postura), de crescimento lento e plumagem do tipo barrada, apresentando o gene que confere barba e costeleta;

- Paraíso Pedrês: proveniente da Granja Aves do Paraíso, Itatiba/SP;

- Embrapa 041: produzido pela Embrapa (Centro Nacional de Pesquisas em Suínos e Aves), Concórdia/SC;

- Label Rouge: produzido pela Granja Globo Aves, Porto Feliz/SP;

- Paraíso Pelado: produzido pela Granja Aves do Paraíso, Itatiba/SP. 
Os quatro primeiros genótipos são materiais experimentais em desenvolvimento desde 1997 no Projeto "Frango Feliz" (ESALQ/USP, Piracicaba/SP) e os demais, materiais comerciais.

Até os 28 dias de idade, todas as repetições receberam alimentação convencional. A partir desta idade e até os 84 dias de idade, os tratamentos consistiram da combinação dos oito genótipos, mantidos em dois programas de alimentação, o primeiro denominado convencional e o segundo, alternativo.

Na Tabela 1 são apresentados os dois tipos de ração, que constituíram completamente e parcialmente as formas convencional e alternativa de alimentação, respectivamente.

No programa convencional, as aves foram alimentadas somente com ração (inicial e de acabamento), enquanto, no programa alternativo, a partir de 28 dias de idade, a ração de acabamento foi substituída gradativamente por quirera de milho e milho em grão integral. O milho, proveniente de um híbrido comercial, continha 9 a $10 \%$ de proteína, 3 a $5 \%$ de extrato etéreo, 70 a $75 \%$ de carboidratos e $12 \%$ de umidade dos grãos. As proporções dos alimentos no sistema de alimentação alternativo são apresentadas na Tabela 2.

Tabela 1 - Composição, níveis de PB e EM das dietas experimentais utilizadas em cada fase do período de criação

Table 1 - Composition, levels of crude protein and metabolizable energy of experimental diets used in each raising period

\begin{tabular}{lcc}
\hline $\begin{array}{l}\text { Ingrediente (\%) } \\
\text { Ingredient (\%) }\end{array}$ & $\begin{array}{c}\text { Ração inicial } \\
(0 \text { a } 28 \text { dias }) \\
\text { Starting diet } \\
(0-28 \text { days })\end{array}$ & $\begin{array}{c}\text { Ração de acabamento } \\
\text { (29 a } 84 \text { dias }) \\
\text { Finishing diet } \\
(29-84 \text { days })\end{array}$ \\
\hline Milho (Corn) & 60,75 & 68,00 \\
Soja (Soybean) & 31,25 & 24,00 \\
Farelo de trigo (Wheat bran) & 2,50 & 2,00 \\
Óleo de soja (Soybean oil) & 0,50 & 1,00 \\
Premix de vit. e min. & 5,00 & 5,00 \\
Vitamin and mineral mix & & 17,00 \\
PB (CP) & 20,00 & 3.150 \\
EM (ME) (kcal/kg) & 3.000 & \\
\hline
\end{tabular}

1 Quantidade/kg de ração (Amount/kg of diet): vit. A - 8.000 U.I.; vit. B12 $15,0 \mathrm{mcg}$; vit. D3 - 3.000 U.L; vit. E - $20,0 \mathrm{mg}$; vit. $\mathrm{K} 3-1,5 \mathrm{mg}$; ácido fólic (folic acid) - 0,6 mg; lisina (lysine) - 0,35 g; metionina (methionine) 1,8 g; Se - 0,2 g; pantotenato de cálcio (calcium pantothenic) - 12,0 mg; niacina (niacine) - 40,0 mg; cloreto de colina (colin chloride) - 0,34 g; biotina (biotin) $100,0 \mathrm{mcg}$; piridoxina (piridoxin) - 3,0 mg; tiamina (thiamine) $2,0 \mathrm{mg}$; riboflavina (riboflavin) - 6,0 mg; antioxidante (antioxidant) 100,0 mg; coccidiostático (coccidiostatic) - 100,0 mg; promotor de crescimento (growth promoter) - 40,0 mg; Cu - 8,0 mg; Fe - 50,0 mg; I - 1,4 mg; $\mathrm{Mn}-72,0 \mathrm{mg} ; \mathrm{Na}-1,6 \mathrm{~g} ; \mathrm{Zn}-54,15 \mathrm{mg}$

2 Quantidade/kg de ração (Amount/kg of diet): vit. A - 6.000 U.I.; vit. B12 10,0 mcg; vit. D3 - 2.000 U.I.; vit. E - 10,0 mg; vit. K3 - 0,8 mg; ácido fólico (folic acid) - 0,4 mg; lisina (lysine) - 0,3 g; metionina (methionine) $1,35 \mathrm{~g}$; Se - 0,2 g; pantotenato de cálcio (calcium pantothenic)- $8,0 \mathrm{mg}$; niacina (niacine) - 20,0 mg; cloreto de colina (colin chloride) - 0,24 g; biotina (biotin) - 60,0 mcg; piridoxina (piridoxin) - 2,0 mg; tiamina (thiamine) - 1,8 mg; riboflavina (riboflavin) - $4,5 \mathrm{mg}$; antioxidante (antioxidant) - 100,0 mg; coccidiostático (coccidiostatic) - $60,0 \mathrm{mg}$; promotor de crescimento (growth promoter) - 30,0 mg; Cu - 6,5 mg; Fe - 50,0 mg; I - 1,0 mg; $\mathrm{Mn}-60,0 \mathrm{mg} ; \mathrm{Na}-1,5 \mathrm{~g} ; \mathrm{Zn}-45,0 \mathrm{mg}$.
Tabela 2 - Proporções (\%) dos constituintes do programa de alimentação alternativo

Table 2 - Percentage (\%) of the constituent in the alternative feeding program

\begin{tabular}{lccc}
\hline $\begin{array}{l}\text { Idade (dias) } \\
\text { Age (days) }\end{array}$ & $\begin{array}{c}\text { Ração de } \\
\text { acabamento } \\
\text { Finishing diet }\end{array}$ & $\begin{array}{c}\text { Quirela de } \\
\text { millho } \\
\text { Tritured corn }\end{array}$ & $\begin{array}{c}\text { Milho em } \\
\text { grão } \\
\text { Corn }\end{array}$ \\
\hline 28 a 35 & 66,6 & 33,4 & 0 \\
35 a 42 & 50,0 & 50,0 & 0 \\
42 a 49 & 33,4 & 66,6 & 0 \\
49 a 56 & 0 & 100 & 0 \\
56 a 63 & 0 & 50,0 & 50,0 \\
63 a 70 & 0 & 33,4 & 66,6 \\
70 a 84 & 0 & 0 & 100 \\
\hline
\end{tabular}

O consumo médio de alimento (CONS) e o peso vivo médio (PVM) foram mensurados aos 28, 56 e 84 dias de idade, enquanto a conversão alimentar (CA) foi calculada com base no CONS e no PVM.

Foi realizada análise descritiva dos dados pelo programa estatístico $\mathrm{SAS}^{\circledR}$, a fim de verificar os pressupostos da análise de variância (teste F), em que se constatou a necessidade de transformar apenas a variável $\mathrm{CA}$, no período 1 (0 a 28 dias), pela escala log na base 10. Para as demais variáveis, não houve necessidade de qualquer tipo de transformação dos dados.

A análise de variância foi realizada pelo procedimento GLM (General Linear Models) do programa estatístico SAS ${ }^{\circledR}$ (SAS, 2005), considerando o modelo estatístico I para o período de 0 a 28 dias e o modelo estatístico II, em esquema fatorial $8 \times 2$ (oito genótipos e dois programas de alimentação), para os períodos de 0 a 56 dias e de 0 a 84 dias:

$$
\begin{gathered}
\mathrm{Y}_{i k}=\mu+\alpha_{i}+\mathrm{e}_{i k}(\mathrm{I}), \\
\mathrm{Y}_{i j k}=\mu+\alpha_{i}+\lambda_{j}+(\alpha \lambda)_{i j}+\mathrm{e}_{i j k}(\mathrm{II}),
\end{gathered}
$$

em que $i=1, \ldots, 8 ; j=1,2 ; k=1,2 ; \mathrm{Y}_{i k}=$ valor observado no $i$-ésimo genótipo da $k$-ésima repetição; $\mathrm{Y}_{i j k}=$ valor observado no $i$-ésimo genótipo e na $j$-ésima alimentação da $k$-ésima repetição; $\mu=$ constante geral a todas as observações; $\alpha_{i}=$ efeito do $i$-ésimo genótipo; $\lambda_{j}=$ efeito da $j$-ésima alimentação; $(\alpha \lambda)_{i j}=$ efeito da interação $i$-ésimo genótipo $\times j$-ésima alimentação; $\mathrm{e}_{i k}=$ efeito aleatório associado ao $i$-ésimo genótipo; $\mathrm{e}_{i j k}=$ efeito aleatório associado ao $i$-ésimo genótipo e à $j$-ésima alimentação, assumindo $\mathrm{e}_{i k}$ ou $\mathrm{e}_{i j k} \sim \mathrm{N}\left(0, \sigma^{2}\right)$, com erros independentes.

Foram obtidas também as médias por meio do comando LSMEANS (quadrados mínimos) apenas para os efeitos significativos de alimentação ou genótipo ou da interação alimentação $\times$ genótipo, sendo comparadas pelo teste Tukey $(\mathrm{P}<0,05)$. 


\section{Resultados e Discussão}

Na Tabela 3 consta a comparação de médias do efeito de genótipo no período de 0 a 28 dias de idade para as variáveis PVM e CA. Para peso vivo médio, foram formados quatro grupos distintos de genótipos: grupo 1 - Caipirão da ESALQ e Paraíso Pedrês; grupo 2 - 7 P; grupo 3 - Embrapa 041; e grupo 4 - Carijó Barbada. A maior $(\mathrm{P}<0,05)$ média foi obtida nos genótipos do grupo 1 .

Os resultados deste trabalho estão de acordo com os encontrados por Takahashi (2003), que, em estudo sobre sistemas de criação, concluiu não haver efeito do sistema de criação (confinamento e piquete) sobre o desempenho e a qualidade da carne de frangos de corte dos tipos colonial e industrial. Esse autor observou diferenças significativas

Tabela 3 - Peso vivo médio e conversão alimentar dos genótipos no período de 0 a 28 dias de idade

Table 3 - $\quad$ Average body weight and feed:gain ratio from 0 to 28 days of age for the genotype effect

\begin{tabular}{lcc}
\hline $\begin{array}{l}\text { Genótipo } \\
\text { Genotype }\end{array}$ & $\begin{array}{c}\text { Peso vivo }(\mathrm{kg}) \\
\text { Body weight }(\mathrm{kg})\end{array}$ & $\begin{array}{c}\text { Conversão alimentar } \\
\text { Feed:gain }^{1} \text { ratio }^{1}\end{array}$ \\
\hline Paraíso Pedrês & $0,752 \mathrm{~A}$ & $1,658 \mathrm{AB}$ \\
Caipirão da ESALQ & $0,725 \mathrm{~A}$ & $1,618 \mathrm{~A}$ \\
7 P & $0,663 \mathrm{~B}$ & $1,622 \mathrm{AB}$ \\
Embrapa 041 & $0,564 \mathrm{C}$ & $1,672 \mathrm{~B}$ \\
Paraíso Pelado & $0,533 \mathrm{CD}$ & $1,622 \mathrm{AB}$ \\
Label Rouge & $0,508 \mathrm{CDE}$ & $1,702 \mathrm{BC}$ \\
Caipirinha da ESALQ & $0,480 \mathrm{DE}$ & $1,761 \mathrm{BC}$ \\
Carijó Barbada & $0,461 \mathrm{E}$ & $1,857 \mathrm{C}$ \\
Média geral (Overall mean) & 0,585 & 1,689 \\
\hline
\end{tabular}

${ }^{1} \mathrm{CA}$ analisada por $\log _{10}(\mathrm{CA})$ mas apresentada na escala original.

Médias seguidas de letras diferentes na coluna diferem pelo teste Tukey $(\mathrm{P}<0,05)$.

${ }^{1} \mathrm{~F} / \mathrm{G}$ was transformed by $\log _{10}(F / G)$ for ANOVA, but presented here in the original scale. Means in the same column followed by different letters differ $(P<0.05)$ by Tukey test. para peso vivo médio entre Paraíso Pedrês e os genótipos Label Rouge e Caipirinha da ESALQ; o genótipo Paraíso Pedrês diferiu $(\mathrm{P}<0,05)$ dos demais, apresentando maior média $(0,743 \mathrm{~kg})$ no período de 0 a 28 dias de idade (consumindo ração comercial).

Os genótipos Caipirão da ESALQ, Embrapa 041 e Carijó Barbada diferiram quanto à conversão alimentar, que foi melhor $(\mathrm{P}<0,05)$ para o Caipirão da $\operatorname{ESALQ}(1,618)$ (Tabela 3). Os resultados encontrados neste trabalho corroboram os obtidos por Takahashi (2003), que não notou diferença significativa para conversão alimentar entre os genótipos Paraíso Pedrês, Label Rouge e Caipirinha da ESALQ no período 0 a 28 dias.

Como demonstrado na Tabela 4 , apesar de a magnitude da diferença entre as médias para um mesmo genótipo nos dois programas de alimentação ter sido relativamente grande, não houve significância para a interação alimentação $\times$ genótipo para peso vivo médio. Entretanto, foram verificadas diferenças significativas $(\mathrm{P}<0,05)$ para os efeitos de alimentação e genótipo isoladamente, com menor $(\mathrm{P}<0,05)$ média para as aves alimentadas alternativamente $(1,29 \mathrm{~kg})$ e maior $(\mathrm{P}<0,05)$ média para o genótipo Paraíso Pedrês $(1,92 \mathrm{~kg})$, que não diferiu do Caipirão da ESALQ.

$\mathrm{Na}$ média dos dois programas de alimentação, os genótipos puderam ser classificados em quatro grupos distintos: grupo 1 - Paraíso Pedrês; grupo 2 - 7 P; grupo 3 - Embrapa 041 e Paraíso Pelado; e grupo 4 - Carijó Barbada. A maior $(\mathrm{P}<0,05)$ média foi apresentada pelo grupo 1 .

Houve efeito significativo $(\mathrm{P}<0,05)$ da interação genótipo $\times$ alimentação sobre a conversão alimentar. Em todos os genótipos, a conversão alimentar foi $23 \%$ melhor $(\mathrm{P}<0,05)$ no programa de alimentação convencional (Tabela 4).

Tabela 4 - Peso vivo médio e conversão alimentar dos genótipos no período de 0 a 56 dias de idade

Table 4 - $\quad$ Average body weight and feed:gain ratio from 0 to 56 days of age for genotype and diet effects

\begin{tabular}{|c|c|c|c|c|c|}
\hline \multirow[t]{3}{*}{$\begin{array}{l}\text { Genótipo } \\
\text { Genotype }\end{array}$} & \multicolumn{3}{|c|}{$\begin{array}{l}\text { Peso vivo }(\mathrm{kg}) \\
\text { Body weight }(\mathrm{kg})\end{array}$} & \multicolumn{2}{|c|}{$\begin{array}{c}\text { Conversão alimentar } \\
\text { Feed:gain ratio }\end{array}$} \\
\hline & \multicolumn{2}{|c|}{$\begin{array}{c}\text { Programa de alimentação } \\
\text { Diet }\end{array}$} & \multirow[t]{2}{*}{$\begin{array}{l}\text { Média geral } \\
\text { Overall mean }\end{array}$} & \multicolumn{2}{|c|}{$\begin{array}{c}\text { Programa de alimentação } \\
\text { Diet }\end{array}$} \\
\hline & $\begin{array}{c}\text { Convencional } \\
\text { Conventional }\end{array}$ & $\begin{array}{l}\text { Alternativo } \\
\text { Alternative }\end{array}$ & & $\begin{array}{c}\text { Convencional } \\
\text { Conventional }\end{array}$ & $\begin{array}{l}\text { Alternativo } \\
\text { Alternative }\end{array}$ \\
\hline Paraíso Pedrês & 2,09 & 1,76 & $1,92 \mathrm{~A}$ & $2,19 \mathrm{Aa}$ & $2,54 \mathrm{Ab}$ \\
\hline Caipirão da ESALQ & 2,10 & 1,66 & $1,88 \mathrm{AB}$ & $2,26 \mathrm{Aa}$ & $2,58 \mathrm{Ab}$ \\
\hline $7 \mathrm{P}$ & 1,98 & 1,52 & $1,75 \mathrm{~B}$ & $2,14 \mathrm{Aa}$ & $2,61 \mathrm{Ab}$ \\
\hline Embrapa 041 & 1,52 & 1,14 & $1,33 \mathrm{C}$ & $2,21 \mathrm{Aa}$ & $2,69 \mathrm{Ab}$ \\
\hline Paraíso Pelado & 1,54 & 1,11 & $1,32 \mathrm{C}$ & $2,08 \mathrm{Aa}$ & $2,76 \mathrm{Ab}$ \\
\hline Label Rouge & 1,46 & 1,04 & $1,24 \mathrm{DC}$ & $2,09 \mathrm{Aa}$ & $2,68 \mathrm{Ab}$ \\
\hline Caipirinha da ESALQ & 1,43 & 1,04 & $1,24 \mathrm{DC}$ & $2,14 \mathrm{Aa}$ & $2,71 \mathrm{Ab}$ \\
\hline Carijó Barbada & 1,35 & 1,04 & $1,19 \mathrm{D}$ & $2,16 \mathrm{Aa}$ & $2,72 \mathrm{Ab}$ \\
\hline $\begin{array}{l}\text { Média geral } \\
\text { Overall mean }\end{array}$ & $1,68 \mathrm{a}$ & $1,29 b$ & & $2,16 \mathrm{a}$ & $2,66 \mathrm{~b}$ \\
\hline
\end{tabular}

Médias seguidas de letras maiúsculas (minúsculas) diferentes na coluna (linha) diferem $(P<0,05)$ pelo teste Tukey.

Means followed by different capital (minor) letters in the same column (row) differ $(P<0.05)$ by Tukey test. 
Tabela 5 - Peso vivo médio e conversão alimentar dos genótipos no período de 0 a 84 dias de idade Table 5 - Average body weight and feed:gain ratio from 0 to 84 days of age for genotype and diet effects

\begin{tabular}{|c|c|c|c|c|}
\hline \multirow[t]{3}{*}{$\begin{array}{l}\text { Genótipo } \\
\text { Genotype }\end{array}$} & \multicolumn{2}{|c|}{$\begin{array}{l}\text { Peso vivo }(\mathrm{kg}) \\
\text { Body weight }(\mathrm{kg})\end{array}$} & \multicolumn{2}{|c|}{$\begin{array}{l}\text { Conversão alimentar } \\
\text { Feed:gain ratio }\end{array}$} \\
\hline & \multicolumn{2}{|c|}{$\begin{array}{c}\text { Programa de alimentação } \\
\text { Diet }\end{array}$} & \multicolumn{2}{|c|}{$\begin{array}{c}\text { Programa de alimentação } \\
\text { Diet }\end{array}$} \\
\hline & $\begin{array}{l}\text { Convencional } \\
\text { Conventional }\end{array}$ & $\begin{array}{l}\text { Alternativo } \\
\text { Alternative }\end{array}$ & $\begin{array}{c}\text { Convencional } \\
\text { Conventional }\end{array}$ & $\begin{array}{l}\text { Alternativo } \\
\text { Alternative }\end{array}$ \\
\hline Caipirão da ESALQ & $3,28 \mathrm{Aa}$ & $1,87 \mathrm{Ab}$ & $2,82 \mathrm{Aa}$ & $3,55 \mathrm{Ab}$ \\
\hline Paraíso Pedrês & $3,20 \mathrm{Aa}$ & $2,05 \mathrm{Ab}$ & $2,81 \mathrm{Aa}$ & $3,42 \mathrm{Ab}$ \\
\hline $7 \mathrm{P}$ & $3,19 \mathrm{Aa}$ & $1,81 \mathrm{Ab}$ & $2,70 \mathrm{Aa}$ & $3,43 \mathrm{Ab}$ \\
\hline Embrapa 041 & $2,55 \mathrm{Ba}$ & $1,24 \mathrm{Bb}$ & $2,55 \mathrm{Aa}$ & $3,78 \mathrm{Ab}$ \\
\hline Paraíso Pelado & $2,51 \mathrm{Ba}$ & $1,25 \mathrm{Bb}$ & $2,74 \mathrm{Aa}$ & $3,75 \mathrm{Ab}$ \\
\hline Caipirinha da ESALQ & $2,42 \mathrm{Ba}$ & $1,22 \mathrm{Bb}$ & $2,66 \mathrm{Aa}$ & $3,69 \mathrm{Ab}$ \\
\hline Label Rouge & $2,36 \mathrm{Ba}$ & $1,23 \mathrm{Bb}$ & $2,65 \mathrm{Aa}$ & $3,62 \mathrm{Ab}$ \\
\hline Carijó Barbada & $2,20 \mathrm{Ba}$ & $1,27 \mathrm{Bb}$ & $2,69 \mathrm{Aa}$ & $3,45 \mathrm{Ab}$ \\
\hline Média geral & $2,63 \mathrm{a}$ & $1,49 \mathrm{~b}$ & $2,70 \mathrm{a}$ & $3,58 \mathrm{~b}$ \\
\hline
\end{tabular}

Médias seguidas de letras maiúsculas (minúsculas) diferentes na coluna (linha) diferem $(\mathrm{P}<0,05)$ pelo teste Tukey.

Means followed by different capital (minor) letters in the same column (row) differ $(P<0.05)$ by Tukey test.

Na Tabela 5 consta a comparação de médias para o efeito da interação genótipo $\times$ programa de alimentação para peso vivo médio e conversão alimentar no período de 0 a 84 dias de idade. Houve efeito significativo $(\mathrm{P}<0,05)$ da interação genótipo $\times$ alimentação sobre o peso vivo médio, confirmando que um mesmo genótipo apresentou comportamento diferenciado entre os programas de alimentação testados ou que, em um mesmo programa de alimentação, houve comportamento diferenciado entre os genótipos testados. Assim, os genótipos alimentados apenas com a dieta convencional ou apenas com a alimentação alternativa formaram dois grupos distintos: o grupo 1 - Caipirão da ESALQ, Paraíso Pedrês e 7 P; e grupo 2 - demais genótipos (Tabela 5). As diferenças mínimas entre esses dois grupos foram de 0,64 e 0,56 kg e as máximas, de 1,08 e $0,83 \mathrm{~kg}$ nos programas convencional e alternativo, respectivamente.

O genótipo Embrapa 041 apresentou a maior diferença de peso vivo médio entre os dois programas de alimentação (Tabela 5), verificando-se redução de 51,4\% no peso vivo médio aos 84 dias de idade das aves alimentadas com o programa alternativo. Por outro lado, o genótipo Paraíso Pedrês demonstrou a menor diferença, registrando-se redução de $36,0 \%$ no peso vivo médio nessa mesma comparação.

Os resultados deste trabalho estão de acordo com os obtidos por Takahashi (2003), que verificou diferenças significativas para peso médio vivo entre Paraíso Pedrês, Label Rouge e Caipirinha da ESALQ. O genótipo Paraíso Pedrês diferiu dos demais e apresentou maior $(\mathrm{P}<0,05)$ média $(3,15 \mathrm{~kg})$ no período de 0 a 84 dias de idade.
Hellmeister Filho et al. (2003), avaliando os efeitos do genótipo e do sistema de criação sobre o desempenho de frangos tipo caipira, observaram que aves criadas no sistema semi-intensivo e alimentadas com ração apresentaram diferença significativa $(\mathrm{P}<0,05)$, em dias, para atingir peso de $2.300 \mathrm{~g}$. Esses autores notaram que o genótipo Label Rouge apresentou a pior $(\mathrm{P}<0,05)$ média (84 dias), seguido de Caipirinha da ESALQ (79 dias), 7 P e Paraíso Pedrês, que não diferiram entre si (62 e 61 dias, respectivamente). Pelos resultados deste trabalho, todos os genótipos avaliados apresentaram aos 84 dias de idade peso vivo médio superior ou inferior a 2.300 g quando alimentados de forma convencional ou alternativa, respectivamente.

O genótipo Embrapa 041 apresentou aos 84 dias de idade peso vivo médio inferior $(2,55 \mathrm{~kg})$ ao obtido por Ávila et al. (2004), que, avaliando níveis de energia metabolizável e dois sistemas de criação (confinado e semiconfinado) para esse genótipo, não encontraram diferença entre os sistemas de criação e os sexos. Aos 84 dias de idade, as aves apresentaram 2,73 e 2,82 kg de PV para 3.000 e $3.200 \mathrm{kcal} / \mathrm{kg}$, respectivamente.

Neste estudo, constatou-se ainda efeito significativo $(\mathrm{P}<0,05)$ da interação genótipo $\times$ programa de alimentação sobre a conversão alimentar, portanto, um mesmo genótipo apresentou comportamento diferenciado entre os programas de alimentação testados. Assim, para todos os genótipos, a conversão alimentar foi pior $(\mathrm{P}<0,05)$, média de 3,58 no programa de alimentação alternativo (Tabela 5). Portanto, as aves do programa de alimentação alternativo apresentaram conversão alimentar $32,6 \%$ pior em relação às do programa de alimentação convencional. 
Estes resultados corroboram os encontrados por Takahashi (2003), que não notou diferença na conversão alimentar entre Paraíso Pedrês, Label Rouge e Caipirinha da ESALQ aos 84 dias de idade. Diferem, no entanto, dos encontrados por Hellmeister Filho et al. (2003), que encontraram diferenças significativas $(\mathrm{P}<0,05)$ para conversão alimentar quando as aves atingiram peso de $2.300 \mathrm{~g}$ de PV. No estudo realizado por esses autores, o genótipo Label Rouge apresentou a pior $(\mathrm{P}<0,05)$ média $(2,50)$ e diferiu de Caipirinha da ESALQ, 7 P e Paraíso Pedrês, que não diferiram entre si.

A partir dos 56 dias de idade, constatou-se a falta de pastagem nos piquetes das aves alocadas no programa alimentar alternativo, o que está associado ao fato de as aves terem recebido a partir dos 49 dias de idade apenas quirera de milho, que, gradativamente, foi substituída por milho em grão.

Este experimento, além de comprovar que a ração não é substituível pelo milho (a substituição pode ocasionar prejuízo drástico para o desempenho dos animais alimentados alternativamente), possibilitou detectar interações entre genótipos e tipos de alimentação. Foi possível detectar a existência de materiais genéticos que apresentam menor perda de PVM (Paraíso Pedrês) quando submetidos a programas de alimentação alternativos.

Pesquisas em áreas afins devem ser desenvolvidas para quantificação dos efeitos da área de pastagem sobre a nutrição das aves, com experimentos que abordem ainda a análise e a viabilidade econômica do sistema semi-intensivo de criação de frangos caipiras.

\section{Conclusões}

Na escolha dos genótipos para criação de frango caipira, devem ser consideradas suas características diferenciadas de desempenho e suas respostas específicas a diferentes programas de alimentação. Tanto no programa de alimentação convencional como no alternativo, os genótipos Caipirão da ESALQ, Paraíso Pedrês e 7 P apresentaram maior peso vivo médio aos 84 dias.

A substituição da ração por milho afetou de forma diferenciada o desempenho dos genótipos avaliados, sendo que Embrapa 041 apresentou a maior perda de peso e aumento da conversão alimentar. O efeito negativo dessa substituição sobre o peso vivo médio e a conversão alimentar foi menor no genótipo Paraíso Pedrês.

\section{Literatura Citada}

ALROE, H.F.; VAARST, M.; KRISTENSEN, E.S. Does organic farming face distinctive livestock welfare issues? A conceptual analysis. Journal of Agriculture and Environmental Ethics, v.14, n.3, p.275-292, 2001.

ÁVIlA, V.S.; FIGUEIREDO, E.A.P.; COLDEBElla, A. et al. Avaliação de níveis de energia metabolizável para frangos de corte tipo caipira ou colonial, "Embrapa 041", em dois sistemas de criação. In: REUNIÃO ANUAL DA SOCIEDADE BRASILEIRA DE ZOOTECNIA, 41., 2004, Campo Grande. Anais... Piracicaba: Sociedade Brasileira de Zootecnia/Unipress, [2004]. (CD-ROM)

BOELLING, D.; GROEN, A.F.; SORENSEN, P. et al. Genetic improvement of livestosk for organic farming systems. Livestock Production Science, v.80, n.1, p.79-88, 2003.

FARMER, L.J.; PERRY, G.C.; LEWIS, P.D. et al. Responses of two genotypes of chicken to the diets and stocking densities of conventional UK and Label Rouge production systems. 2. Sensory attributes. Meat Science, v.47, n.1-2, p-77-93, 1997.

FIGUEIREDO, E.A.P.; ÁVILA, V.S. Produção agroecológica de frangos de corte e galinhas de postura. Concórdia: Embrapa Suínos e Aves, 2001. 185p.

FIGUEIREDO, E.A.P.; PAIVA, D.P.; ROSA, P.S. et al. Diferentes denominações e classificação brasileira de produção alternativa de frangos. In: SIMPÓSIO SOBRE PRODUÇÃO ALTERNATIVA DE FRANGOS. CONFERÊNCIA APINCO DE CIÊNCIA E TECNOlogia AVÍCOlAS, Campinas. Anais... Campinas: Fundação Apinco de Ciência e Tecnologias Avícolas, 2001. v.2, p.209-222.

GESSULLI, O.P. Avicultura alternativa: sistema "ecologicamente correto" que busca o bem-estar animal e a qualidade do produto final. Porto Feliz: OPG Editores, 1999. 217p.

HELLMEISTER FILHO, P.; MENTEN, J.F.M.; SILVA, M.A.N. et al. Efeito de genótipo e do sistema de criação sobre o desempenho de frangos tipo caipira. Revista Brasileira de Zootecnia, v.32, n.6, p.1883-1889, 2003 (supl. 2).

HERMANSEN, J.E. Organic livestock production systems and appropriate development in relation to public expectations. Livestock Production Science, v.80, n.1, p.3-15, 2003.

LEWIS, P.D.; PERRY, G.C.; FARMER, L.J. et al. Responses of two genotypes of chicken to the diets and stocking densities typical of UK and "Label Rouge" production systems. 1. Performance, behaviour and carcass composition. Meat Science, v.45, n.4, p-501-516, 1997.

LUND, V.; RÖCKLINGSBERG, H. Outlining a conception of animal welfare for organic farming systems. Journal of Agriculture and Environmental Ethics, v.14, n.4, p.391-424, 2001.

SILVA, R.D.M.; NAKANO, M. Sistema caipira de criação de galinhas. Piracicaba: O Editor, 1998. 110p.

STATISTICAL ANALYSES SYSTEM - SAS. SAS OnlineDoc ${ }^{\circledR}$ Disponível em: <http://www.id.unizh.ch/software/unix/statmath/ sas/sasdoc/stat/index.htm> Acesso em: 12/12/2005.

STRINGHETA, P.C.; MUNIZ, J.N. Alimentos orgânicos. Viçosa, MG: Editora UFV, 2004. p.37-128.

TAKAHASHI, S.E. Efeito do sistema de criação sobre o desempenho e a qualidade de carne de frangos de corte tipo colonial e industrial. Botucatu: Universidade Estadual Paulista, 2003. 64p. Dissertação (Mestrado em Nutrição e Produção Animal) - Universidade Estadual Paulista, 2003.

Recebido: 24/01/06 Aprovado: 12/12/06 